RU Годовые отчеты банковских учреждений: структура, прагматика и языковая аранжировка

\author{
Дрожащих А. B.
}

Аннотация. Цель исследования - выявить прагматические и структурно-языковые особенности жанра годового отчета, получившего широкое распространение в современных банковских коммуникациях. Научная новизна исследования заключается в том, что впервые в отечественной лингвистике тексты жанра «годовой отчет» рассматриваются на стыке взаимодействия языка и культуры с привлечением русскоязычного эмпирического материала. В результате исследования определено место годовых отчетов в пространстве банковского дискурса, выявлена национально-культурная специфика русскоязычного годового отчета, представлена стандартная структурная модель текстов указанного жанра, а также показана многоплановость коммуникативно-прагматической установки годовых отчетов банковских учреждений и описаны языковые средства ее реализации.

\title{
EN Annual Reports of Banking Institutions: Structure, Pragmatics and Linguistic Features
}

\author{
Drozhashchikh A. V.
}

\begin{abstract}
The paper aims to identify the pragmatic and structural-linguistic features of the annual report genre which is widespread in the modern banking communications. The scientific originality of the research lies in the fact that it considers the texts of the "annual report" genre at the interface of language and culture interaction involving Russian-language empirical data for the first time in Russian linguistics. As a result, the place of the annual reports in the space of banking discourse has been identified, the national and cultural specificity of Russian-language annual reports has been revealed, the standard structural model of the texts which belong to the genre under consideration has been presented, and also the multiplicity of the communicative-pragmatic nature of annual reports of banking establishments has been shown and the language means of its realization have been described.
\end{abstract}

\section{Введение}

Актуальность настоящего исследования обусловлена тем, что корпоративные годовые отчеты представляют одну из наименее разработанных областей деловой жанрологии в современной отечественной лингвистике. Обращение к данной тематике позволяет включить в практику лингвистического анализа новый эмпирический материал и дает возможность рассмотреть некоторые важные аспекты институциональной коммуникативной культуры российского банковского сообщества, определить роль годовых отчетов в банковских коммуникациях и описать прагматическую и структурно-языковую специфику текстов указанного жанра в социально-информационной сфере русскоязычного банковского дискурса. Такой ракурс исследования позволяет более полно раскрыть информационно-воздействующий потенциал годовых отчетов российских банковских учреждений, ориентированных на достижение банком своих частных PR-интересов в общем контексте социально обусловленных коммуникативных задач.

В работе поставлены следующие задачи:

- рассмотреть жанр «годовой отчет» как социолингвистический феномен, отражающий базовые культурные ценности, нормы и правила общения банковского сообщества;

- установить конститутивные признаки жанра «годовой отчет» и сферу его функционирования в рамках русскоязычного банковского дискурса;

- определить особенности структурно-композиционной организации текстов годового отчета, выявить и систематизировать языковые средства, участвующие в реализации информационной установки и PR-установки годового отчета в русскоязычном банковском дискурсе. 
Многоаспектность жанра «годовой отчет» предполагает использование взаимодополняющих методов исследования с опорой на дискурс-анализ, ориентированный как на выявление специфики банковской интеракции с целевыми аудиториями и описание интралингвистических характеристик текстов указанного жанра, так и на анализ экстралингвистического фона. Привлечение отдельных процедур контент-анализа и критического анализа дискурса позволяет оценить и интерпретировать содержательный план годовых отчетов российских банковских учреждений и вскрыть их манипуляционные возможности в современном медиаконтексте.

Теоретической базой послужили работы отечественных и зарубежных языковедов В. В. Дементьева (2010), А. Д. Кривоносова (2001), Т. Ю. Махортовой (2007), Т. Н. Хомутовой (2004) по теории речевых жанров, а также работы Ю. В. Данюшиной (2012), А. О. Стеблецовой (2004), Т. А. Ширяевой (2008), V. К. Bhatia (1995) по теории делового дискурса, С. Г. Тер-Минасовой (2007), Е. B. de Groot (2008), G. Hofstede (1991) по теории межкультурной коммуникации и Е. Е. Анисимовой (2003), А. Г. Сонина (2006) по теории поликодовых текстов.

Материалом исследования послужили годовые отчеты Сбербанка, Альфа-Банка, Газпромбанка и других ведущих российских банковских учреждений за 2014-2020 гг. объемом 700 страниц. Выбор годовых отчетов в качестве объекта исследования связан с общей недостаточной изученностью русскоязычного банковского дискурса и специфики речевых жанров, играющих ключевую роль в публичных банковских коммуникациях. Изучение текстов жанра «годовой отчет» с позиций бизнес-лингвистики позволяет более точно и адекватно понять ценностные приоритеты и особенности коммуникативного взаимодействия коммерческих банков с различными целевыми аудиториями в публичной сфере и повысить эффективность обработки и декодирования банковских сообщений, что представляется важным в условиях бурного развития банковского дела на рубеже XX-XXI вв.

Практическая значимость статьи заключается в том, что результаты исследования могут найти применение в дальнейших исследованиях по теории речевых жанров и теории межкультурной коммуникации, в курсах лингвистической прагматики и стилистики, а также в лингводидактике и практике преподавания делового русского языка в плане оптимизации языкового материала и отбора текстов по специальности.

\section{Основная часть}

В зарубежной лингвистике речевому жанру «годовой отчет» посвящено много специальных исследований. В существующих работах, выполненных преимущественно на материале английского языка, рассматриваются общая архитектоника и важные текстовые сегменты годовых отчетов (Garzone, 2006; Rutherford, 2005), а также прагматика (Thomas, 1997), дискурсивные стратегии (Mignini, 2007) и лексическо-грамматическая аранжировка текстов указанного жанра (Bu, Connor-Linton, Wang, 2020; Wang, Li, 2012). В значительно меньшей степени корпоративные годовые отчеты изучаются в рамках межкультурного подхода и организационной семиотики, хотя отдельные исследования проводятся и в этом направлении (De Groot, 2008).

B российском языковедении проблематика корпоративных годовых отчетов не получила детального рассмотрения, хотя годовые отчеты являются важным специальным жанром институционального дискурса и представляют большой интерес с лингвистической точки зрения. С одной стороны, годовой отчет принадлежит к смешанной деловой речи и обладает стилевыми характеристиками, присущими деловым текстам, финансово-бухгалтерской документам и текстам PR-направленности (Malavasi, 2007). По характеру передаваемой информации годовые отчеты обнаруживают очевидные параллели с такими профессиональными жанрами, как квартальные отчеты, аналитические презентации, релизы для СМИ и материалы к годовым собраниям акционеров. С другой стороны, рассматриваемые тексты правомерно рассматривать как поликодовые или креолизованные тексты (Анисимова, 2003), так как помимо вербальной составляющей они включают невербальные элементы визуально-графического характера (таблицы, графики, фотографии и другие изобразительные элементы и т.д.), значительно повышающие креационистские и экспланаторные потенции годовых отчетов.

Представляется, что годовые отчеты играют важную роль в русскоязычном банковском дискурсе и являются одним из основных инструментов, обеспечивающих коммуникативное взаимодействие банка с различными аудиториями. Годовые отчеты предназначены для акционеров и инвесторов, однако потребителем отчетной информации могут быть и другие социальные группы (аналитики рынка, органы власти, общественность, клиенты и сотрудники организации). При этом известно, что годовой отчет является корпоративной публикацией, в которой составители отчета выражают в тексте отчета не собственные, а корпоративные оценки и суждения (Кривоносов, 2001).

Годовые отчеты российских банковских учреждений обладают всеми признаками речевого жанра и характеризуются общностью коммуникативно-прагматической установки, стиля, содержания, структуры и лексикограмматического наполнения. Конститутивными признаками жанра «годовой отчет» являются высокая информационная плотность, подчеркнутая объективность и общая сдержанность изложения, а также коммерческая вежливость и официальность. Как свидетельствует наша выборка, русскоязычные банковские годовые отчеты отличаются большим объемом и сложным структурно-композиционным построением. По сути, годовой отчет можно рассматривать как своеобразный макротекст, состоящий из ряда отдельных объединенных общей тематикой самостоятельных законченных микротекстов. В соответствии с действующим законодательством РФ главная задача текстов рассматриваемого жанра состоит в том, чтобы дать достоверную информацию о деятельности и финансовых результатах банка за отчетный год. Стандартный годовой отчет российского банка включает следующие основные разделы: 
- отчет руководящих органов банка;

- положение банка в отрасли и итоги года для бизнес-направлений;

- бухгалтерская (финансовая) отчетность банка;

- социальный отчет;

- заключение независимого аудитора;

- информация о персональном составе Совета директоров и Правления банка;

- адреса филиалов и отделений банка и иные сведения справочного характера.

Как правило, отдельные структурно-композиционные части годового отчета расположены в строго определенном порядке, и подобная четкая формальная организация текста облегчает адресату поиск нужной информации. В принципе в корпус текста могут быть введены и другие данные с тем, чтобы компетентно и аргументированно отразить специфику деятельности, успехи и достижения банковского учреждения в удобной для потребителя информации форме.

Современная лингвистика учит, что дискурсивные практики и языковые средства, используемые в профессиональной коммуникации, предопределены прагматическими доминантами профессиональных сообееств (Солнышкина, Казачкова, Калинкина 2015, с. 166) и базовыми культурными ценностями и практиками, нормами и правилами общения, принятыми носителями определенной лингвокультуры (Тер-Минасова, 2007, с. 117). На выбор языковых решений составителей годовых отчетов российских банков оказывают влияние культурно-коммуникативные макрокатегории статусно-ориентированного характера с упором на статусность и дистантность в отношениях с клиентом, а также коллективизм русской культуры и менталитета, в рамках которых успех воспринимается как плод коллективных усилий, а результаты совместной деятельности предполагают обязательность солидарной ответственности. Например: Команда Банка уделяла пристальное внимание поддержке прибыльности и эффективности всех направлений бизнеса (Альфа-Банк, 2020, с. 25). При этом, согласно нашим наблюдениям, в годовых отчетах российских банков повествование ведется в отстраненном ракурсе от 3 лица - банковского учреждения, которое фигурирует в тексте под своим корпоративным названием или вводится с помощью собирательных имен «банк» или «группа». Например: С целью ограничения валютных рисков, принимаемых «Запсибкомбанк» $\mathrm{OAO}$, в Банке применяется система установления лимитов и ограничений (Запсибкомбанк, 2014, с. 38). Собирательные имена традиционно используются и при наименовании клиентуры в связи с остаточной востребованностью институциональных дискурсивных практик периода централизованной экономики и отношением к потребителям банковских услуг как к общей недифференцированной массе. Например: Основным направлением деятельности Банка в 2019 году стали кредитование населения через собственные клиентские центры... и привлечение средств населения в депозиты и в сберегательные счета (Почта Банк, 2019, с. 6).

Вместе с тем в русскоязычные годовые отчеты начинают проникать ценности западного индивидуализма и практика местоименного общения, принятая в англоязычной коммуникативной культуре для сокращения дистанции между участниками коммуникативного процесса, создания эффекта персонифицированного общения адресанта с адресатом и передачи информации в форме, характерной для бытового дискурса (Hussain, Ali, Kazim, 2020). Формы личных и притяжательных местоимений 1 лица являются частотными в годовых отчетах Альфа-Банка и Сбербанка и очень заметны, например, в обращении Председателя Правления Сбербанка Г. Грефа: Mы запустили сервис SberPaу, обновили тарифы Р2P переводов, расширили доступность эквайринга

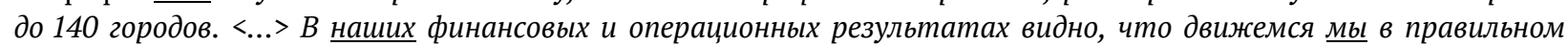
направлении, и крайне важно, что люди, работающие у нас, получают удовлетворение от результата (Сбербанк, 2020, с. 26). Примечательно, что в англоязычной версии годового отчета топ-менеджеры российских банков нередко переходят даже на особый сокращенный вид прямого общения с целевыми аудиториями от 1 лица единственного числа, что помогает адресанту показать личную власть и компетентность, а также представить себя в качестве лидера компании: I would like to review 2019 by looking at several themes of the 2019 results before briefly looking ahead sharing some of our goals (Тинькофф Банк, 2019, с. 10). / Перед тем как вкратце рассказать вам о наших планах на будущее, мне хотелось бы обсудить итоги 2019 года и остановиться на некоторых результатах работы нашего банка в отчетном году (здесь и далее перевод выполнен автором статьи. - А. Д.).

Преимущественная ориентация на адресата-профессионала объясняет широкое функционирование в русскоязычных годовых отчетах терминологической лексики, количественных числительных и аббревиатур, характерных для языка российского банковского сообщества. При этом терминологический аппарат годового отчета включает однокомпонентные и многокомпонентные термины ряда частных экономических дисциплин, таких как кредитование, валютно-биржевые операции, денежные средства, ценные бумаги, бухгалтерский учет, маркетинг. В количественном плане превалирует бухгалтерская и собственно банковская терминология, которая оказывается особенно востребованной в ключевых разделах годового отчета «позиции банка на рынке», «пояснения к финансовой отчетности банка», «финансовая отчетность банка» и «заключение независимого аудитора». Интересно, что российские банки могут включать в корпус годового отчета специальный терминологический глоссарий ключевых терминов и аббревиатур, что сокращает риск коммуникативных неудач и упрощает процесс восприятия адресатом узкоспециальной информации.

Многие используемые в русскоязычных годовых отчетах специальные термины типа букраннер, бэк-офис, кешбэк, инсайдер, маркет-мейкер, овердрафт, опцион, скоринговая оценка заемщиков, факторинг, хеджирование рисков, эквайринг карт имеют англо-американское происхождение. Включение подобной специальной лексики (в том числе и в оригинальном правописании) в текст отчета, по-видимому, преследует цель подчеркнуть 
актуальность рассматриваемой тематики и продемонстрировать продвинутость и респектабельность банковского учреждения и его способность поддерживать контакт с контрагентами на профессиональном языке международного банковского сообщества.

Помимо терминологии, характерной для подъязыка банковского дела, вербальными маркерами текстов рассматриваемого жанра также являются количественные числительные, обеспечивающие фактологичность и объективность изложения, а также аббревиатуры и сокращения, повышающие плотность подачи отчетной информации. В годовых отчетах имена числительные встречаются практически повсеместно: в фрагментах финансовой отчетности, в текстовых сегментах констатирующего и разъяснительного характера, в текстовых сегментах, нацеленных на аргументативную экземплификацию достижений организации, а также в таблицах, графиках и диаграммах с целью фокусировки внимания адресата на количественных показателях деятельности банковского учреждения. Например: В кредитном портфеле «Запсибкомбанк» ОАО на 01.01.15 числится 186,3 тысяч кредитных договоров (Запсибкомбанк, 2014, с. 33); Капитал банка увеличился на 600 млн \$ - до $\underline{8.7}$ млрд \$ (Альфа-Банк, 2020 , с. 19). Аббревиатуры и сокращения представлены инициальными аббревиатурами и сокращениями с усечением начальной, серединной или конечной части исходного слова или словосочетания. Как правило, данные сокращения используются в годовых отчетах для обозначения денежных сумм и валют, наименования банковских институтов и их подразделений (млн. - миллион, млрд. - миллиард, Банк России - Центральный Банк Российской Федерации, ВВП - внутренний валовый продукт, ВСП - внутреннее структурное подразделение, ВЭД - внешнеэкономическая деятельность, МВФ - Международный валютный фонд и др.).

Помимо решения собственно информационных задач, корпоративные годовые отчеты выполняют и ряд других функций (просветительская функция, организационно-директивная функция и т.д.). Специалисты считают, что современные годовые отчеты банковских постепенно эволюционируют в сторону профессиональных жанров, используемых для поддержания связей с общественностью, укрепления отношений с акционерами и инвесторами, создания позитивного корпоративного имиджа в массовом сознании (Махортова, 2007). Большой интерес в плане формирования и поддержания позитивного имиджа проявляют российские банковские учреждения, полагая, что в условиях возрастающей конкуренции корпоративный имидж становится важным средством борьбы за привлечение новых клиентов на рынках банковских услуг. В проблемных ситуациях тексты жанра «годовой отчет» становятся эффективным инструментом банка для нейтрализации информационных акций конкурентов и реагирования на финансовые скандалы, отток клиентуры и иные проблемы экономического и этического порядка.

Проведенный анализ показывает, что для годового отчета в принципе характерна оптимистическая тональность изложения. В информационной части годового отчета находит отражение исключительно позитивная новостная тематика, а сведения негативного характера либо просто отсутствуют, либо описываемая ситуация преподносится таким образом, что негативное развитие событий невозможно было предвидеть или предсказать. Важное место в самопрезентации российского банка занимает позитивно заряженная лексика в сочетании с элементами рациональной аргументации (цифровые данные, статистические выкладки и т.д.). В частности, вербальными маркерами успешности организации на рынке банковских услуг являются лексема «успех», специальные термины типа «прибыль» и «доход», а также нейтральная лексика, указывающая на рост экономических и финансовых показателей. Например: Банк успешно реализовал 24 крупнейшие сделки объемом на 15 млрд рублей и выше для 16 корпоративных эмитентов (Газпромбанк, 2019, с. 8); Чистая прибыль выросла до рекордных 1, 347 млрд \$ (Альфа-Банк, 2020, с. 19); В 2019 году Банк показал значительный рост основных бизнес-показателей (Почта Банк, 2019, с. 4).

При конструировании положительного образа организации в информационной части годовых отчетов российских банков широко задействована и другая стратегия, ориентированная на эмоциональную сферу сознания адресата, с привлечением имен существительных и прилагательных с семантикой доминирования и исключительности, форм суперлатива и наречных интенсификаторов, подчеркивающих конкурентоспособность, результативность и динамизм банковского учреждения, его позитивные корпоративные ценности «надежность», «командный дух», «ответственность», «открытость». Например: ВТБ Капитал - бесспорный лидер инвестиционно-банковского рынка (ВТБ Банк, 2017, с. 11); Альфа-Банк получил престижную премию FinAward от делового журнала «Банковское обозрение» за кредитную карту «100 дней без процентов» (Альфа-Банк, 2020, с. 5); Третий год подряд Альфа-Банк - самый быстрорастущий банк на российском рынке (Альфа-Банк, 2020, с. 19). Усилению прагматического воздействия на получателя отчетной информации способствует инкорпорированные в текст имена собственные, передающие широкий спектр имплицитных и фоновых значений и смыслов, ориентированных на поддержание благоприятного имиджа банка:

- официальные названия авторитетных деловых партнеров банка, позволяющих последнему навязывать целевой аудитории имидж солидного финансово-кредитного учреждения (Газпром, Роснефть, Норникель, группа ПРОДО и др.);

- официальные названия известных рейтинговых агентств, позволяющих банку наращивать доверие со стороны целевой аудитории (международные рейтинговые агентства S\&P Global Ratings, Fitch Ratings, Moody’s Investors Service и др.);

- названия банковских продуктов и услуг, позволяющие банку подчеркнуть их уникальность и технологичность (сервисы SberPay, Direct@Pay, GPI-трекинг валютных платежей и др.).

Наконец, для решения имиджевых задач в годовых отчетах российских банков применяются и стратегии манипулятивного воздействия, эксплуатирующие синкретичность текстов рассматриваемого жанра (Bhatia, 1995). 
Действительно, переплетение элементов финансового, бухгалтерского и PR-дискурса в рамках единого документа - годового отчета является неслучайным и имеет целью представить речевые ходы PR-направленности такими же объективными и достоверными, что и собственно финансовые показатели, прошедшие экспертизу со стороны аудиторов. Например: Благодаря проведению «Запсибкомбанк» ОАО гибкой политики по установлению конкурентоспособных процентных ставок по депозитам юридических и физических лии, а также активному участию в тендерах по обслуживанию «зарплатных проектов», оперативной работе по обновлению линейки срочных вкладов населения прирост ресурсов на клиентские счета составил 1396,6 млн руб. до 79 364,1 млн руб. (Запсибкомбанк, 2014, с. 28).

Следует отметить, что в годовых отчетах российских банков в отношении разных целевых групп применяются специфические приемы воздействия. Так, в рамках статусно-ролевых отношений «банк-акционер», «банкинвестор», «банк-финансовый аналитик» предлагается аргументация, рассчитанная на профессионалов, а именно привлекательная финансовая отчетность банка и положительное заключение независимой аудиторской компании. Для реципиентов-непрофессионалов и представителей широкой общественности в текст отчета вводятся качественная нефинансовая информация, отражающая ценностные ориентиры банковского учреждения (корпоративная культура, благотворительная деятельность, экологические проекты, социальные программы и т.д.) и визуальные элементы, призванные усилить привлекательность банка и подчеркнуть его мощь, традиции, локальную идентичность и приоритетную зону деловой активности.

\section{Заключение}

Таким образом, в результате проведенного анализа мы приходим к следующим выводам. Годовые отчеты российских банков играют важную роль в русскоязычном банковском дискурсе и являются одним из основных инструментов, обеспечивающих коммуникативное взаимодействие банка с различными целевыми аудиториями в публичной сфере. Конститутивными признаками текстов рассматриваемого жанра выступают высокая информационная плотность, подчеркнутая объективность и общая сдержанность изложения, а также коммерческая вежливость и официальность.

Годовые отчеты отличаются поликодовостью, сложной структурно-композиционной организацией и отражают российские и западные культурные ценности, нормы и правила общения. Данные тексты являются не только ценным источником получения деловой информации о реальном положении того или иного хозяйствующего субъекта, но и обладают существенным PR-потенциалом для формирования корпоративного имиджа и выстраивания доверительных отношений с целевыми аудиториями через использование технологий косвенного и манипуляционного воздействия. При конструировании позитивного образа российские банки применяют широкий спектр языковых средств, включая личные местоимения 1 лица, позитивно заряженную лексику, имена существительные и прилагательные с семантикой доминирования и исключительности, формы суперлатива и наречия-интенсификаторы.

Перспективы дальнейшего исследования связаны с изучением новейших трендов в использовании годовых отчетов и особенно невербальной составляющей данных корпоративных публикаций в деловой коммуникативно-речевой практике. Представляется, что специфика применяемых коммерческими организациями в годовых отчетах манипулятивных технологий воздействия на адресата с целью решения собственных PR-задач также требует дальнейшего уточнения на базе более объемного и разнопланового эмпирического материала.

\section{Источники | References}

1. Анисимова Е. Е. Лингвистика текста и межкультурная коммуникация (на материале креолизованных текстов). М.: Издательский центр «Академия», 2003.

2. Годовой отчет банка «Альфа-Банк». 2020. URL: https://alfabank.gcdn.co/media/about/annual_report/AlfaBank_ annual_report_2020.pdf

3. Годовой отчет банка «ВТБ-Банк». 2017. URL: https://www.vtb.ru/akcionery-i-investory/raskrytie-informacii/ godovoj-i-socialnyi-otchet/

4. Годовой отчет банка «Газпромбанк». 2019. URL: https://www.gazprombank.ru/gbo-2019/

5. Годовой отчет банка «Запсибкомбанк». 2014. URL: https://www.zapsibkombank.ru/upload/iblock/351/god-otshet_ 2015_rusverssion.pdf

6. Годовой отчет банка «Почта Банк». 2019. URL: https:/www.pochtabank.ru/upload/images/documents/ annualreport_2019.pdf

7. Годовой отчет банка «Сбербанк». 2020. URL: https://www.sberbank.ru//common/img/uploaded/_new_site/com/ gosa2021/yr-sber-ar20-rus.pdf

8. Годовой отчет банка «Тинькофф-Банк». 2019. URL: https://acdn.tinkoff.ru/static/documents/a3b94ad6-61ab-416cb4f2-d89726fd8194.pdf

9. Кривоносов А. Д. Жанры PR-текста. СПб.: Изд-во СПБГУ, 2001.

10. Махортова T. Ю. Лингвопрагматический потенциал PR-жанра в пространстве банковского дискурса (на материале немецкоязычных банковских проспектов): автореф. дисс. ... к. филол. н. Волгоград, 2007. 
11. Солнышкина М. И., Казачкова М. Б., Калинкина Т. Е. Эклектика институционального дискурса: норм или нарушение? // Филологические науки. Вопросы теории и практики. 2015. № 12. Ч. 1.

12. Тер-Минасова С. Г. Война и мир языков и культур. М.: АСТ; Акварель; Хранитель, 2007.

13. Bhatia V. K. Genre-mixing in professional communication: The case of 'private intentions' vs. 'socially recognized purposes'// Explorations in English for Professional Communication. Hong Kong: City University of Hong Kong, 1995.

14. Bu H., Connor-Linton J., Wang L. Linguistic Variation in the Discourse of Corporate Annual Reports: A MultiDimensional Analysis // Discourse Studies. 2020. Vol. 22. № 6.

15. Garzone G. Letter to Shareholders and Chairman's Statements: Textual Variability and Generic Integrity // Genre Variation in Business Letters. Bern: Peter Lang, 2006.

16. Groot E. B. de. English Annual Reports in Europe: A Study on the Identification and Reception of Genre Characteristics in Multimodal Annual Reports Originating in the Netherlands and in the United Kingdom. Utrecht: LOT, 2008.

17. Hussain S., Ali M., Kazim Z. A Review on the Rhetorical Structure and Linguistic Features of Corporate Annual Reports // International Journal of Academic Research in Business and Social Sciences. 2020. Vol. 10 (9). № 2.

18. Malavasi D. Promotion in Banks' Annual Reports: an Integrated Analysis of Genre, Evaluative Lexis and Institutional Identity. Modena: Il Fiorino, 2007.

19. Mignini M. Strategic Maneuvering in Banks' Annual Reports // Proceedings of the 6th Conference of the International Society for the Study of Argumentation. Amsterdam, 2007.

20. Rutherford B. A. Genre Analysis of Corporate Annual Report Narratives: a Corpus Linguistics-Based Approach // Journal of Business Communication. 2005. Vol. 34. № 1.

21. Thomas J. Discourse in the Marketplace: the Making of Meaning in Annual Reports // Journal of Business Communication. 1997. Vol. 42. № 4 .

22. Wang H., Li L. Lexical Features in Corporate Annual Reports: a Corpus-Based Study // European Journal of Business and Social Sciences. 2012. № 8.

\section{Информация об авторах | Author information}

RU Дрожащих Александр Владимирович ${ }^{1}$, к. филол. н., доц.

${ }^{1}$ Государственный аграрный университет Северного Зауралья, г. Тюмень

EN Drozhashchikh Alexander Vladimirovich ${ }^{1}, \mathrm{PhD}$

${ }^{1}$ Northern Trans-Ural State Agricultural University, Tyumen

${ }^{1}$ dalexv2012@rambler.ru

\section{Информация о статье | About this article}

Дата поступления рукописи (received): 08.11.2021; опубликовано (published): 28.12.2021.

Ключевые слова (keywords): тексты жанра «годовой отчет»; банковский дискурс; прагматика; композиционные особенности; лексико-грамматическая аранжировка; texts of "annual report” genre; bank discourse; pragmatics; compositional features; lexical-grammatical arrangement. 